Revista Calidad en la Educación Superior

Programa de Autoevaluación Académica

Universidad Estatal a Distancia, Costa Rica

ISSN 1659-4703

revistacalidad@uned.ac.cr

\title{
INFLUENCIA DE LAS VARIABLES DE ADMISIÓN SOBRE EL ÉXITO ACADÉMICO EN EL PRIMER AÑO DE LA CARRERA DE LICENCIATURA EN MEDICINA Y CIRUGÍA DE UCIMED
}

\author{
INFLUENCE OF THE VARIABLES OF ADMISSION ON ACADEMIC SUCCESS IN THE FIRST \\ YEAR FOR A DEGREE IN MEDICINE AND SURGERY AT UCIMED
}

\author{
Hilda M. Sancho Ugalde ${ }^{1}$ \\ hmsancho@yahoo.com \\ Juan Carlos Vanegas Pissa ${ }^{2}$ \\ pissacr2011@gmail.com \\ Universidad de Ciencias Médicas (UCIMED), Costa Rica
}

\author{
Volumen 7, Número 1 \\ Mayo 2016 \\ pp.301 - 320
}

Recibido: 9 de setiembre, 2015

Aprobado: 22 de abril, 2016

\footnotetext{
1 Profesora emérita de la UCR. Doctora en Medicina y Cirugía. Maestría en Ciencias Biomédicas. Laboró como docente en la carrera de Medicina y Cirugía en la Universidad de Costa Rica y en la Universidad de Ciencias Médicas. Actualmente es Coordinadora de la Unidad de Aseguramiento de la Calidad Académica, Universidad de Ciencias Médicas y forma parte de los grupos de pares nacionales e internacionales para acreditación de carreras o universidades de las agencias SINAES y CONEAUPA. Experiencia como investigadora en el área de neurociencias. Asesorías en procesos de acreditación de educación superior a nivel nacional e internacional. Correo electrónico: hmsancho@yahoo.com

${ }^{2}$ Licenciado en Matemáticas y Física, Universidad de los Llanos. Egresado del programa de maestría en Bioestadística, Universidad de Chile. Maestría académica en Estadística, Universidad de Costa Rica. Laboró como docente en La Maestría en Salud Pública en la Universidad de Costa Rica, en la Escuela de Biología de la Universidad Nacional y en la Universidad de Ciencias Médicas. Actualmente es el estadístico de la Universidad de Ciencias Médicas. Consultor externo para el Estado de La Nación y de la Educación. Par acreditador nacional del SINAES. Colaborador en la parte estadística del grupo investigador del Dr. Misael Chinchilla de la UCIMED. Correo electrónico: pissacr2011@gmail.com
} 
Influencia de las variables de admisión sobre el éxito académico en el primer año de la carrera de Licenciatura en Medicina y Cirugía de UCIMED

Hilda M. Sancho Ugalde, Juan C. Vanegas Pissa

\section{Resumen}

El presente trabajo tiene como objetivo evaluar la capacidad predictiva de las variables sociodemográficas y del proceso de admisión como factores que incidan sobre el éxito académico de los estudiantes que cursan el primer semestre de la carrera de Licenciatura en Medicina y Cirugía, de la Universidad de Ciencias Médicas (UCIMED), Costa Rica. La población objetivo está integrada por los alumnos de nuevo ingreso de las cohortes 2009 a 2013 inclusive, ( $N=1558$ estudiantes). Se definió el éxito académico como la aprobación del total de cursos del primer semestre de la carrera; y mediante la estadística descriptiva y la técnica multivariada de Regresión Logística, se determinó la incidencia que tienen los diferentes factores, de índole socioeconómica y propios del proceso de admisión como predictoras del éxito académico. Los resultados permiten concluir que las variables significativas del éxito académico son las calificaciones en la prueba de conocimientos y el promedio de los dos últimos años de secundaria y haber tomado la decisión de estudiar con un mayor tiempo de reflexión.

Palabras clave: Éxito Académico; Criterios de Admisión; Regresión Logística; Indicadores de Ingreso; Estudiantes de Medicina

\section{Abstract}

This study aims to assess the predictive ability of the sociodemography variables and the admissions process, as factors that affect the academic success of students in the first semester of the bachelor of medicines and surgery. The target population is composed of 20092013 freshmen cohorts ( $N 1558$ students) Academic success as the approval of all courses in the first half of career was defined; and using descriptive statistics and multivariate logistic regression technique, the incidence that different factors, socio-economic measure, and the process of admission itself as predictors of academic success were determined. The results suggest that the significant variables of academic success are the scores on the admission general test and the average of the last two years of high school.

Keywords: Academic Success; Admission criteria; Logistic Regression; Indicators of Income; Medical students.

\section{Introducción}

En Costa Rica, como en el resto del mundo, se ha producido un aumento en la demanda de la educación universitaria debido a la presión demográfica y a la variación de sus índices educativos a nivel de secundaria, (UNESCO, 1998, 2006; Banco Centroamericano de Integración Económica, 2010 \& Programa Estado de la Nación, 2013). Cambios que conducen al análisis de la importancia de garantizar una formación académica de calidad que a la vez disminuya tanto la deserción, como la repitencia a nivel universitario (Tünnermann, 2010). 
Es así como los procesos de admisión a las universidades se focalizan dentro del debate, con el objetivo de seleccionar y retener al mayor número de estudiantes y a la vez obtener graduados de alta calidad.

Por lo anterior, se establecen criterios que permitan predecir las capacidades requeridas para obtener el éxito académico, tanto en los cursos propios de la carrera, como en su posterior desempeño como profesional (Di Gresia, Porto \& Ripani, 2002).

La Licenciatura en Medicina y Cirugía, tanto a nivel internacional como nacional, se caracteriza por ser una carrera con alta demanda en sus estudiantes, no solo por la dedicación de tiempo académico, sino porque deben tener una serie de atributos personales. Los procesos de selección son exigentes, y como señala Santelices, (2007), focalizados en el alumno de alto desempeño académico, poseedor de capacidades para desenvolverse en medios y ambientes altamente demandantes. Además, están basados en los antecedentes de la experiencia académica de enseñanza media y el rendimiento en pruebas cuantitativas (de conocimientos y aptitudes) y cualitativas (entrevista personal o pruebas psicológicas), que permiten realizar una selección de aspirantes, ante el significativo aumento de la demanda de ingreso (De Garay \& Sánchez, 2011; Díaz \& Toloza, 2007; Jara et al., 2008; Kay-Lambkin, Pearson, \& Rolfe, 2002; Rodríguez \& Gómez, 2010).

En la Universidad de Ciencias Médicas (UCIMED), el proceso de admisión es único, basado en méritos académicos, el cual, evalúa la trayectoria académica durante la secundaria, por medio de dos pruebas; una cognitiva, que aborda el conocimiento matemático, biológico, químico general y del lenguaje; y la psicométrica, para valorar aspectos de aptitud espacial, numérica, razonamiento abstracto y verbal y memoria. Las aptitudes de liderazgo, y trabajo bajo presión, se evalúan por medio de una entrevista personal. En este proceso se admiten estudiantes de instituciones secundarias públicas y privadas, nacionales y extranjeras, del área rural y urbana, con amplio espectro de edad. Se admiten los mejores puntajes obtenidos en el proceso, teniendo así, estudiantes con mayor probabilidad de éxito académico, y a la vez se 
detecta en forma temprana, si se requiere algún tipo de apoyo académico, financiero o de otra naturaleza por parte de la Universidad. Por otra parte, la evaluación del éxito académico en los cursos del primer semestre se obtiene mediante pruebas escritas, orales, de desempeño, en talleres, laboratorios y seminarios, de ahí se derivan notas emitidas en una escala de cero a cien, con una aprobación mínima para cada una de setenta puntos.

\section{Justificación de la escogencia del grupo a evaluar}

Se estudió el grupo de alumnos de nuevo ingreso, durante el periodo 2009-2013, porque permite hacer un seguimiento más cercano del total de cursos que matricularon durante ese semestre, todos son cursos similares que comprenden los conocimientos de Biología, Matemáticas, Química general, Idioma español; las metodologías de enseñanza y las técnicas de aprendizaje son semejantes: lecciones magistrales, evaluaciones escritas, presentación de temas por parte de los estudiantes, uso de análisis basado en problemas, utilización de mapas conceptuales, actividades prácticas.

Además, el primer año de estudios determina que el estudiante se adapte a las exigencias de los estudios universitarios, y a un nuevo ambiente social. La posibilidad de continuar estudios o no, se da en ese periodo, por lo que el abandono y la reprobación son consecuencias de su desempeño dentro del mismo.

Este análisis permite hacer la relación entre los resultados académicos de los cursos del primer semestre de la carrera de Licenciatura en Medicina y Cirugía, algunas variables de tipo sociodemográfico, experiencia académica previa al ingreso y resultados académicos en el primer semestre de la carrera.

La población estudiada estuvo compuesta por 1558 estudiantes, que ingresaron al primer año de la carrera de Licenciatura en Medicina y Cirugía, en el primero y segundo periodo académico, en el lapso 2009-2013. Se midieron los resultados académicos obtenidos en los cursos regulares del primer semestre que son de carácter obligatorio, por lo que, queda definido el total de cursos y créditos que debe matricular. Se incluyeron los estudiantes que 
Influencia de las variables de admisión sobre el éxito académico en el primer año de la carrera de Licenciatura en Medicina y Cirugía de UCIMED

Hilda M. Sancho Ugalde, Juan C. Vanegas Pissa

aprobaron todas las materias matriculadas en el primer semestre de la carrera (tuvieron éxito académico) o reprobaron al menos un curso y los aprobados por suficiencia. Se excluyeron los estudiantes que tuvieron cursos convalidados, equiparados internamente y aquellos que tuvieron algún tipo de retiro (justificado, injustificado, abandono).

\section{Criterios de estudio: Definición de variables}

La variable dependiente bajo estudio, en este caso, es el éxito académico. Cuya definición según diversos autores se relaciona con aspectos cuantitativos, como el promedio de materias aprobadas anualmente, o con el cumplimiento de las metas, logros u objetivos establecidos en la asignatura que está cursando un alumno, además es un indicador del éxito / fracaso académico (Di Gresia et al., 2002; Vélez \& Roa, 2005).

En este estudio se asigna a la variable dependiente - éxito académico (EA) - dos categorías, según el número de asignaturas semestrales aprobadas por el estudiante: si ha aprobado el total de cursos del primer semestre, le corresponde la categoría "1" y si ha reprobado al menos una materias, se le asigna la categoría "0".

Las variables independientes o factores considerados en este estudio y cuyo grado de incidencia sobre el éxito académico se pretende determinar fueron: año de ingreso, edad de ingreso a la UCIMED, periodo de ingreso (I / II semestre), sexo, condición del estudiante (activo / inactivo), región o procedencia geográfica (Valle Central/ fuera el Valle Central), puntaje obtenido en la prueba de conocimientos realizada por la Universidad, puntaje obtenido en la pruebas psicométricas, promedio de las calificaciones obtenidas en los dos últimos años de la secundaria, promedio general del proceso de ingreso, matrícula del total de cursos del primer semestre (si / no), número de asignaturas matriculadas, matrícula en bloque completo.

\section{Metodología}

Es un estudio comparativo, retrospectivo, descriptivo, longitudinal y poblacional de los resultados obtenidos en las investigaciones realizadas en un periodo de cinco años (2009- 
Influencia de las variables de admisión sobre el éxito académico en el primer año de la carrera de Licenciatura en Medicina y Cirugía de UCIMED

Hilda M. Sancho Ugalde, Juan C. Vanegas Pissa

2013) de estudiantes de primer ingreso en la facultad de medicina de una universidad privada, que recibe estudiantes nacionales y extranjeros.

Los datos se tomaron de la base de datos de la Institución que tiene la información sobre el proceso de admisión y las variables sociodemográficas, culturales y educacionales, previas a su ingreso a la Facultad, así como los puntajes obtenidos en los cursos del primer semestre de la carrera. Se definió como variable dependiente éxito académico y operacionalmente como la aprobación del total de las materias que integran el primer semestre del primer año de la carrera.

Las variables independientes o predictoras de la dependiente fueron:

1. Año de ingreso.

2. Edad de ingreso a la UCIMED.

3. Periodo de ingreso (I / II semestre).

4. Sexo.

5. Condición del estudiante (activo / inactivo).

6. Región o Procedencia geográfica (Valle Central / fuera del Valle Central).

7. Puntaje obtenido en la prueba de conocimientos realizada por la Universidad.

8. El puntaje obtenido en la pruebas psicométricas.

9. Promedio de las calificaciones obtenidas en los dos últimos años de la secundaria.

10. Promedio general del proceso de ingreso

11. Matrícula del total de cursos del primer semestre (Si / No).

12. Número de asignaturas matriculadas.

13. Matrícula en bloque completo.

\section{Análisis estadístico}

Para caracterizar el grupo de estudio se utilizó estadística descriptiva. Los análisis de la distribución de frecuencia se calcularon para examinar la relación del sexo y la edad al ingreso sobre el éxito académico estudiantil. Para estimar las variables que inciden sobre el éxito académico, se ajustó un modelo de regresión logística. Se eliminaron las variables que 
Influencia de las variables de admisión sobre el éxito académico en el primer año de la carrera de Licenciatura en Medicina y Cirugía de UCIMED

Hilda M. Sancho Ugalde, Juan C. Vanegas Pissa

presentaron colinealidad con otras, y las que no fueron significativas en el proceso de regresión por pasos (regresión stepwise) para estimar el mejor modelo (sexo, condición de estudiante, promedio general del proceso de ingreso, número de asignaturas matriculadas y si matriculo bloque completo o no). La medida Conteo ajustado de $\mathrm{R}^{2}$ indica que el modelo tiene un 22,0\% de capacidad para predecir el éxito académico (Adj Count $R^{2}=0,220$ ). Las pruebas de bondad de ajuste chi-cuadrado y la Hosmer-Lemeshow, (Hosmer \& Lemeshow, 2000), prueban la hipótesis nula Ho: Los valores observados y predichos son iguales, con valores de $p=0,4940$ y $p=0,8769$ respectivamente; es decir, se cumplen el supuesto mediante las dos pruebas.

El modelo utilizado muestra un buen nivel de ajuste y es válido para predecir, de acuerdo con Aldrich \& Nelson (1984) y Press \& Wilson (1978), citados por García, Alvarado \& Jiménez (2000, p.249), señalando que:

La regresión logística es una técnica adecuada cuando se pretende hacer una clasificación basada en las características de los datos. Una ventaja adicional de esta técnica es que no requiere la normalidad estricta de los datos, y además, un gran número de investigaciones han evidenciado que hay otras muchas características deseables que hacen de la regresión logística una mejor herramienta para la categorización que el análisis discriminante (p.249).

Se utilizó un total de 1558 estudiantes que ingresaron entre los años 2009 al 2013 en el primero y segundo periodo académico y completaron todo el proceso de admisión para la carrera de Medicina. Se excluyeron los convalidados, los de retiro justificado, los de retiro por abandono, los de equiparación interna, y dos casos de datos incompletos. La distribución por año y relativa se muestra en el Cuadro 1 y Gráfico 1. 
Cuadro 1. Distribución absoluta y relativa del número de estudiantes de nuevo ingreso a la carrera de Medicina y Cirugía entre los años 2009 al 2013. UCIMED.

\begin{tabular}{|c|c|c|}
\hline Año & Estudiantes & Porcentaje \\
\hline 2009 & 264 & 16,9 \\
\hline 2010 & 295 & 18,9 \\
\hline 2011 & 354 & 22,7 \\
\hline 2012 & 370 & 23,7 \\
\hline 2013 & 275 & 17,7 \\
\hline Total & $\mathbf{1 5 5 8}$ & $\mathbf{1 0 0 , 0}$ \\
\hline
\end{tabular}

Fuente: Base datos UCIMED, 2014.

Gráfico 1. Distribución absoluta y relativa del número de estudiantes de nuevo ingreso a la carrera de Medicina y Cirugía entre los años 2009 al 2013. UCIMED.

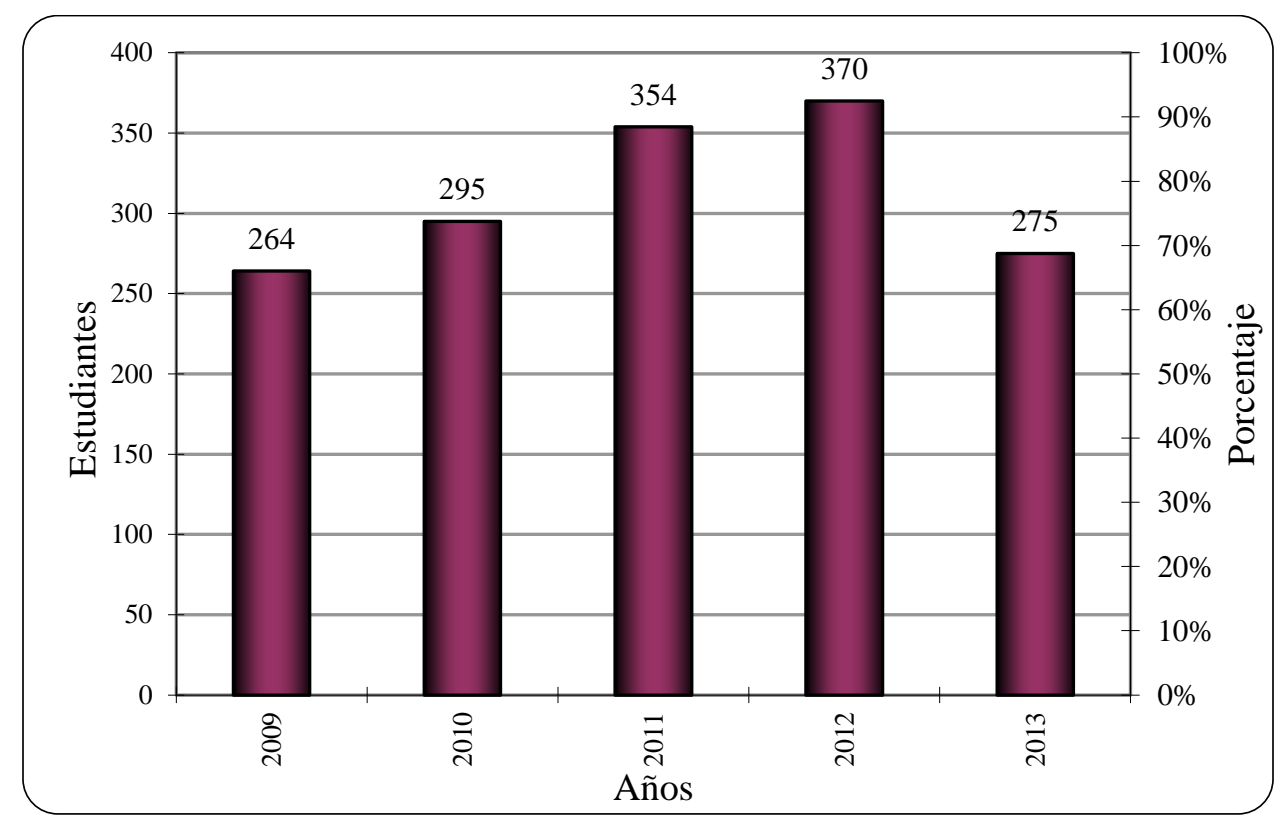

Fuente: Base datos UCIMED, 2014.

\section{Resultados}

Los resultados al aplicar la regresión logística paso a paso, con respecto a las variables significativas en el éxito académico, al analizar una de ellas, dejando las demás fijas, después de eliminar aquellas que presentaron colinealidad y estandarizar los coeficientes; se pueden observar en el Cuadro 2. 


\section{Cuadro 2. Influencia de las variables independientes sobre el éxito académico de los} estudiantes de primer ingreso en el primer año de carrera. Licenciatura en la carrera de Medicina. UCIMED 2009-2013.

\begin{tabular}{|l|c|c|c|c|c|c|c|}
\hline \multicolumn{1}{|c|}{ Éxito Académico } & $\begin{array}{c}\text { Odds } \\
\text { Ratio }\end{array}$ & $\begin{array}{c}\text { Error } \\
\text { estándar }\end{array}$ & $\mathbf{z}$ & $\mathbf{P}>|\mathbf{z}|$ & \multicolumn{2}{|c|}{$\begin{array}{c}\text { Intervalo } \\
\text { confianza del } \\
\mathbf{9 5 \%}\end{array}$} & $\begin{array}{c}\text { Coeficientes } \\
\text { estandarizados }\end{array}$ \\
\hline Año ingreso & 1,50 & 0,0881 & 6,94 & 0,000 & 1,3389 & 1,6849 & 1,7279 \\
\hline Periodo ingreso & 0,43 & 0,0702 & $-5,17$ & 0,000 & 0,3100 & 0,5900 & 0,6975 \\
\hline Edad & 1,08 & 0,0343 & 2,30 & 0,021 & 1,0109 & 1,1455 & 1,1614 \\
\hline Promedio notas colegio & 1,07 & 0,0117 & 6,41 & 0,000 & 1,0496 & 1,0955 & 1,5385 \\
\hline Región de residencia & 1,82 & 0,3740 & 2,93 & 0,003 & 1,2205 & 2,7265 & 1,1978 \\
\hline $\begin{array}{l}\text { Puntaje obtenido prueba } \\
\text { conocimientos }\end{array}$ & 1,10 & 0,0082 & 12,90 & 0,000 & 1,0854 & 1,1177 & 2,8173 \\
\hline $\begin{array}{l}\text { Puntaje obtenido prueba } \\
\text { de aptitud }\end{array}$ & 1,01 & 0,0056 & 2,61 & 0,009 & 1,0036 & 1,0258 & 1,2174 \\
\hline
\end{tabular}

Fuente: Base datos UCIMED, 2014.

\section{Año de ingreso a la UCIMED}

Por cada incremento en una unidad del año de ingreso, la razón de tener éxito académico aumenta 1.5 veces, teniendo las demás variables fijas, con un coeficiente estandarizado alto, constituyéndose así en la segunda variable que más pesa para tratar de explicar el éxito académico de los estudiantes de primer ingreso (coeficiente estandarizado), este resultado podría deberse a características propias del estudiante o de la enseñanza en la Institución,Así podría estar relacionado con el hecho de que el estudiante del segundo semestre, por lo general, ha tenido más tiempo de reflexión para tomar su decisión de ingreso, por lo cual estaría más identificado con la carrera escogida, además de haber dispuesto de un periodo de varios meses para tener otras experiencias vitales, tales como pasantías en otros países relacionadas con sus intereses educativos. En lo propio de la UCIMED, semestralmente y en forma continua, se realiza un análisis de los resultados de las diversas actividades de aprendizaje y las técnicas utilizadas en los cursos conduciendo a una actualización y mejoría que es aplicada en el semestre posterior inmediato. 
Influencia de las variables de admisión sobre el éxito académico en el primer año de la carrera de Licenciatura en Medicina y Cirugía de UCIMED

Hilda M. Sancho Ugalde, Juan C. Vanegas Pissa

\section{Periodo de ingreso (I / II semestre)}

Matricular en el primer periodo académico disminuye la razón de tener éxito académico en 0,43 veces, con un coeficiente estandarizado bajo, comparados con los que matriculan en el segundo periodo. Este factor podría deberse a que los alumnos del segundo semestre han tenido una experiencia vital social, que les permite una mayor adaptabilidad a la demanda que les presentan los estudios universitarios. Guarda relación con lo encontrado en el variable año de ingreso y podría estar señalando una mayor madurez del individuo.

\section{Edad de ingreso a la UCIMED}

El promedio de edad al ingreso es de 18,0 $\pm 2,0$ años, con un ámbito de 16 a 44 años (Cuadro 3) (Gráfico 2). Este dato refleja al sistema nacional educativo, toda vez que el ingreso a las universidades se da luego de la graduación en los estudios secundarios, no existen cursos requisito para el ingreso a la carrera de Medicina y Cirugía, tal como se observa en países anglosajones y europeos. En Latinoamérica el ingreso es directo después del colegio y las edades son semejantes a las obtenidas en este estudio (Carrión, 2002; De Garay \& Sánchez, 2011; Vélez \& Roa, 2005). Esta variable no influye sobre el éxito académico.

Cuadro 3. Estadísticas descriptivas de la edad (años) de los estudiantes de nuevo ingreso a la carrera de Medicina entre los años 2009 al 2013. UCIMED.

\begin{tabular}{|c|c|c|c|c|c|}
\hline Año & Estudiantes & Promedio & $\begin{array}{c}\text { Desviación } \\
\text { estándar }\end{array}$ & Mínimo & Máximo \\
\hline $\mathbf{2 0 0 9}$ & 264 & 17,7 & 1,3 & 16,0 & 26,0 \\
\hline $\mathbf{2 0 1 0}$ & 295 & 18,1 & 2,4 & 16,0 & 44,0 \\
\hline $\mathbf{2 0 1 1}$ & 354 & 18,3 & 2,3 & 16,0 & 40,0 \\
\hline $\mathbf{2 0 1 2}$ & 370 & 18,0 & 2,2 & 16,0 & 37,0 \\
\hline $\mathbf{2 0 1 3}$ & 275 & 18,0 & 1,6 & 16,0 & 28,0 \\
\hline Total & 1558 & 18,0 & 2,0 & 16,0 & 44,0 \\
\hline
\end{tabular}

Fuente: Base datos UCIMED, 2014. 


\section{Gráfico 2. Estadísticas descriptivas de la edad (años) de los estudiantes de nuevo} ingreso a la carrera de Medicina entre los años 2009 al 2013. UCIMED.

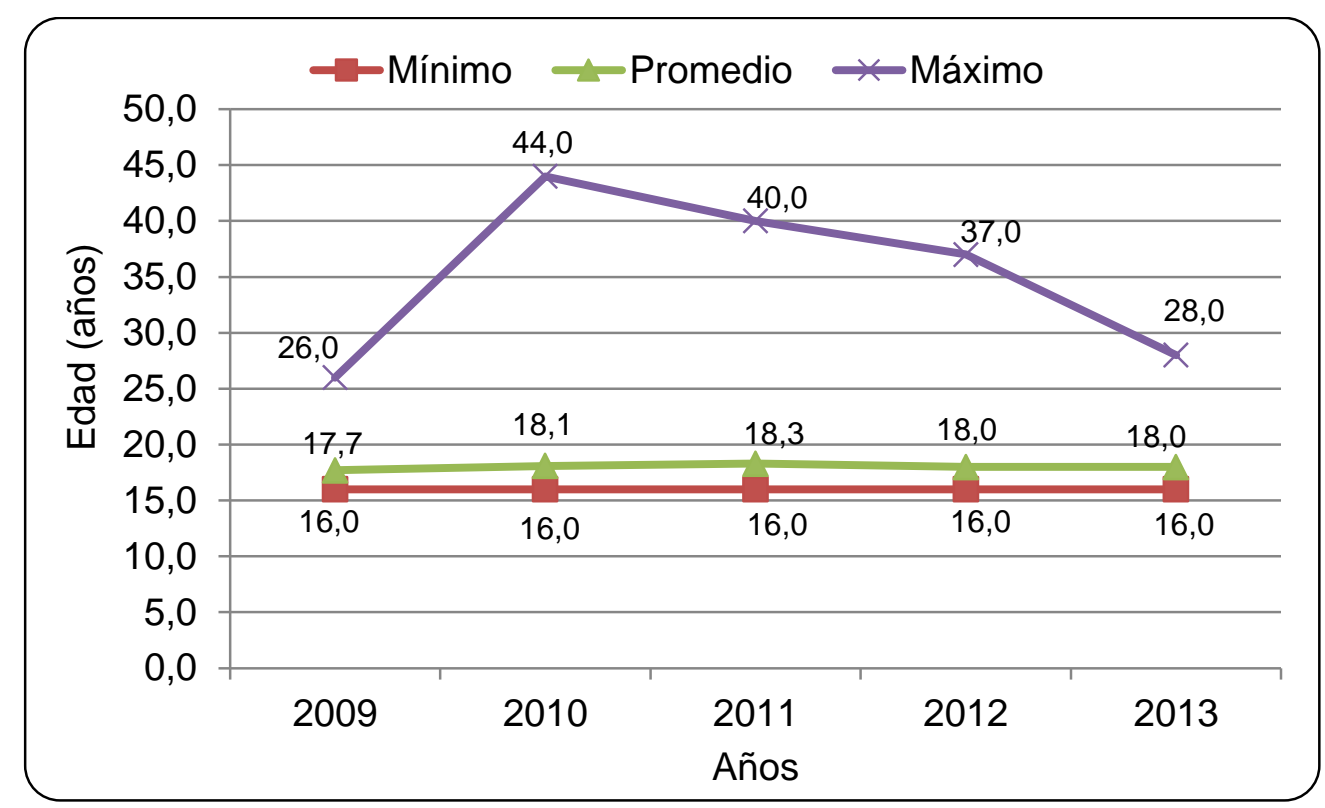

Fuente: Base datos UCIMED, 2014.

\section{Promedio de las calificaciones obtenidas en los dos últimos años de la secundaria}

La relación del promedio obtenido en el colegio y con ser exitoso o no, se observa en el Cuadro 4. Los estudiantes que fueron exitosos obtuvieron en promedio $88,0 \pm 6,0$ puntos sobre 100 , mientras que los estudiantes no exitosos obtuvieron en promedio $84,7 \pm 6,0$ puntos sobre 100. Es importante destacar que la variabilidad en los dos grupos es la misma.

\section{Cuadro 4. Estadísticas descriptivas del promedio del colegio de los estudiantes de} nuevo ingreso a la carrera de Medicina, según éxito académico. UCIMED.

\begin{tabular}{|c|c|c|c|}
\hline $\begin{array}{c}\text { Éxito } \\
\text { Académico }\end{array}$ & Estudiantes & Promedio & $\begin{array}{c}\text { Desviación } \\
\text { estándar }\end{array}$ \\
\hline No & 477 & 84,7 & 6,0 \\
\hline Si & 1081 & 88,0 & 6,0 \\
\hline
\end{tabular}

Fuente: Base datos UCIMED, 2014.

Estos datos están señalando que la eficiencia de los resultados de la educación secundaria al ingreso, influye en los resultados de su trayectoria en la universidad y apoyan que los 
Influencia de las variables de admisión sobre el éxito académico en el primer año de la carrera de Licenciatura en Medicina y Cirugía de UCIMED

Hilda M. Sancho Ugalde, Juan C. Vanegas Pissa

exámenes de ingreso tienen así un papel relevante en el sistema de acceso a las universidades, y en lo particular para las carreras de Medicina. Aspecto que también en Estados Unidos se valora, cuando señalan que las variables de ingreso pueden sugerir éxito académico en el ciclo básico, no así en el desempeño clínico (Carrión, 2002)

El análisis de regresión logística indica que por cada incremento en una unidad en el promedio obtenido en el colegio, la razón de tener éxito académico aumenta 1,07, con un coeficiente estandarizado de 1.5, y lo localiza como la tercera variable que más pesa para explicar el éxito académico en los estudiantes de primer ingreso. Resultado que está de acuerdo con lo hallado por García et al. (2000) y por Rodríguez, Díaz, Moreno \& Bacallao (2000), citados por Ibarra \& Michalus (2010, p. 41), que lo señalan como el factor más relevante a la hora de predecir el desempeño en el primer año de carrera.

\section{Región de residencia o Procedencia geográfica (Valle Central / Fuera del Valle Central)}

La UCIMED recibe estudiantes de todo el país, para el análisis se hizo una división por procedencia geográfica de las provincias de Valle Central que comprenden a San José, Alajuela, Heredia, y Cartago y las que están fuera de él: Puntarenas, Limón y Guanacaste. Un total de $1412(90 \%)$ estudiantes proceden del Valle Central y $156(10 \%)$ fuera del Valle Central.

El análisis con regresión logística revela que por región se tiene un 1.8 de posibilidades de tener éxito académico, pero el coeficiente estandarizado es de 1,1978, así la procedencia de provincias del Valle Central no es un factor que incida fuertemente entre los que apoyan el éxito académico, lo cual difiere de lo indicado por otros autores, que señalan que la población de origen rural tiene menos posibilidades de alcanzar el éxito académico. Los colegios a nivel de áreas urbanas son al parecer de mejor calidad académica en sus programas y demandas de hábitos de estudio para los estudiantes, tal como lo refiere Vélez \& Roa (2005, p.79) citando los estudios de Mizala, Romaguera \& Reinaga (2005), Asimismo, difieren de los resultados de Iturra \& Soto (2013) y Santos et al. (2010). 
Sin embargo, en este caso, el número de estudiantes provenientes de zonas rurales es muy bajo, solo del 10\%, lo cual explicaría estos resultados; también se justificaría con el hecho que este grupo de estudiantes, tal como lo analizamos en un estudio previo, (Sancho \& Vanegas, 2015) tiene mayor apoyo académico dentro de su familia, al ser hijos de padres profesionales por lo que la procedencia geográfica, no hace diferencias entre ellos. (Kay-Lambkin et al., 2002).

\section{Puntaje obtenido en la prueba de conocimientos realizada por la Universidad}

Con respecto al puntaje obtenido en la prueba de conocimientos y su relación con ser exitoso o no, se observa que los estudiantes que fueron exitosos obtuvieron en promedio 59,5 $\pm 9,8$ puntos sobre 100, mientras que los estudiantes no exitosos obtuvieron en promedio $50,2 \pm 9,9$ puntos sobre 100 (Cuadro 5). El 25\% de los estudiantes exitosos obtuvieron 66,0 puntos 0 más en la prueba de conocimientos, mientras que los no exitosos obtuvieron 57,0 puntos o más. Es importante destacar que la variabilidad en los dos grupos es muy similar. La prueba de conocimientos evalúa los campos de las ciencias, que a su vez son aquellos de los primeros cursos de la carrera de Medicina y Cirugía. Así, una buena formación en estas áreas permite tener mayores posibilidades de éxito en el primer año de la carrera, resultados que están de acuerdo con los trabajos de Richardson, Winder, Briggs \& Tyderman (1998); Meleca (1995) y Díaz, Valdés, Hernández, Nápoles, Fajardo (2001), citados por Díaz \& Toloza (2007, p.60). De igual manera, evidenciado por los trabajos de De Garay \& Sánchez (2011), quien utilizando un modelo de regresión, mostró que esta variable incidió de manera positiva en el rendimiento escolar de los estudiantes.

Cuadro 5. Estadísticas descriptivas del puntaje total de la prueba de conocimientos de los estudiantes de nuevo ingreso a la carrera de Medicina, según éxito académico.

UCIMED.

\begin{tabular}{|c|c|c|c|}
\hline $\begin{array}{c}\text { Éxito } \\
\text { Académico }\end{array}$ & Estudiantes & Promedio & $\begin{array}{c}\text { Desviación } \\
\text { estándar }\end{array}$ \\
\hline No & 477 & 50,2 & 9,9 \\
\hline Si & 1081 & 59,5 & 9,8 \\
\hline
\end{tabular}

Fuente: Base datos UCIMED, 2014. 
Este factor, de acuerdo con el análisis de regresión, incide 1,10 veces más sobre la posibilidad de tener éxito, por cada unidad que aumente en el puntaje obtenido en la prueba de conocimientos, y a su vez fue la que presentó mayor peso en el modelo con un coeficiente estandarizado de 2.8. Hallazgos semejantes a los de De Garay \& Sánchez (2011) y Carrión (2002).

\section{Puntaje obtenido en la prueba de aptitud académica}

Las pruebas psicométricas evalúan aptitud espacial, aptitud numérica, razonamiento verbal y abstracto, y memoria. Todas son características que se han señalado como importantes para la carrera de Medicina y Cirugía. Se valoran mediante la aplicación de la prueba de Evaluación Factorial de las Aptitudes Intelectuales. Sin embargo, en los resultados obtenidos con el modelo de regresión logística, tal como se observa en el cuadro 2 , se obtiene un coeficiente estandarizado de 1,2174 indicando que su incidencia no es fuerte en la probabilidad de éxito académico durante el primer semestre de la carrera.

\section{Promedio general del proceso de ingreso}

Esta variable presentó colinealidad. Se obtiene mediante la ponderación de las calificaciones obtenidas en los dos últimos años de la secundaria, la prueba cognitiva y psicométrica, y la entrevista personal o prueba psicológica. Esta calificación permite ordenar al total de estudiantes, de mayor a menor calificación y es a partir de la misma que se escogen aquellos que ingresan a la institución de acuerdo con el número de plazas que se han determinado para ese periodo.

La relación del promedio general con el éxito académico indica que los estudiantes que fueron exitosos tuvieron en promedio $62,7 \pm 6,6$ puntos sobre 100 , mientras que los estudiantes no exitosos tuvieron en promedio $58,1 \pm 7,2$ puntos sobre 100 . Como se observa en el Cuadro 6.

La matrícula del total de cursos del primer semestre (cinco), el número de asignaturas matriculadas y la matricula en bloque completo también presentaron colinealidad en el modelo. 
Cuadro 6. Estadísticas descriptivas del promedio general de la prueba de admisión de los estudiantes de nuevo ingreso a la carrera de Medicina, según éxito académico. UCIMED.

\begin{tabular}{|c|c|c|c|}
\hline $\begin{array}{c}\text { Éxito } \\
\text { Académico }\end{array}$ & Estudiantes & Promedio & $\begin{array}{c}\text { Desviación } \\
\text { estándar }\end{array}$ \\
\hline No & 477 & 58,1 & 7,2 \\
\hline Si & 1081 & 62,7 & 6,6 \\
\hline
\end{tabular}

Fuente: Base datos UCIMED, 2014.

\section{Sexo}

Esta variable presentó colinealidad. El predomino femenino en la carrera de Medicina y Cirugía se ha venido describiendo en los diferentes estudios realizados, los cuales reflejan que el ingreso de mujeres a nivel universitario ha aumentado (De Garay \& Sánchez 2011; Carrión 2002; IESALC-UNESCO, 2008). En esta investigación los resultados indican que el 57,9\% son mujeres, al discriminarlos por año estas proporciones oscilan entre el 55,0\% y el $63,0 \%$ aproximadamente. Es decir, hay una relación aproximada de 6 mujeres a 4 hombres, como se puede observar en el Cuadro 7 y Gráfico 3. Esta tendencia ha sido señalada por Boucourt \& González (2006) en Venezuela, Panamá, Francia, México y España; y por Javariz (2007) en Puerto Rico.

Cuadro 7. Distribución absoluta y relativa del sexo de los estudiantes de nuevo ingreso a la carrera de Medicina entre los años 2009 al 2013. UCIMED.

\begin{tabular}{|c|c|c|c|}
\hline Año & Sexo & Estudiantes & Porcentaje \\
\hline \multirow{2}{*}{2009} & Femenino & 156 & 59,1 \\
\cline { 2 - 4 } & Masculino & 108 & 40,9 \\
\hline \multirow{2}{*}{2010} & Femenino & 165 & 55,9 \\
\cline { 2 - 4 } & Masculino & 130 & 44,1 \\
\hline \multirow{2}{*}{2011} & Femenino & 196 & 55,4 \\
\cline { 2 - 4 } & Masculino & 158 & 44,6 \\
\hline \multirow{2}{*}{2012} & Femenino & 211 & 57,0 \\
\cline { 2 - 4 } & Masculino & 159 & 43,0 \\
\hline \multirow{2}{*}{2013} & Femenino & 174 & 63,3 \\
\cline { 2 - 4 } & Masculino & 101 & 36,7 \\
\hline
\end{tabular}

Fuente: Base datos UCIMED, 2014. 


\section{Gráfico 3. Distribución relativa del sexo de los estudiantes de nuevo ingreso a la carrera de Medicina entre los años 2009 al 2013. UCIMED.}

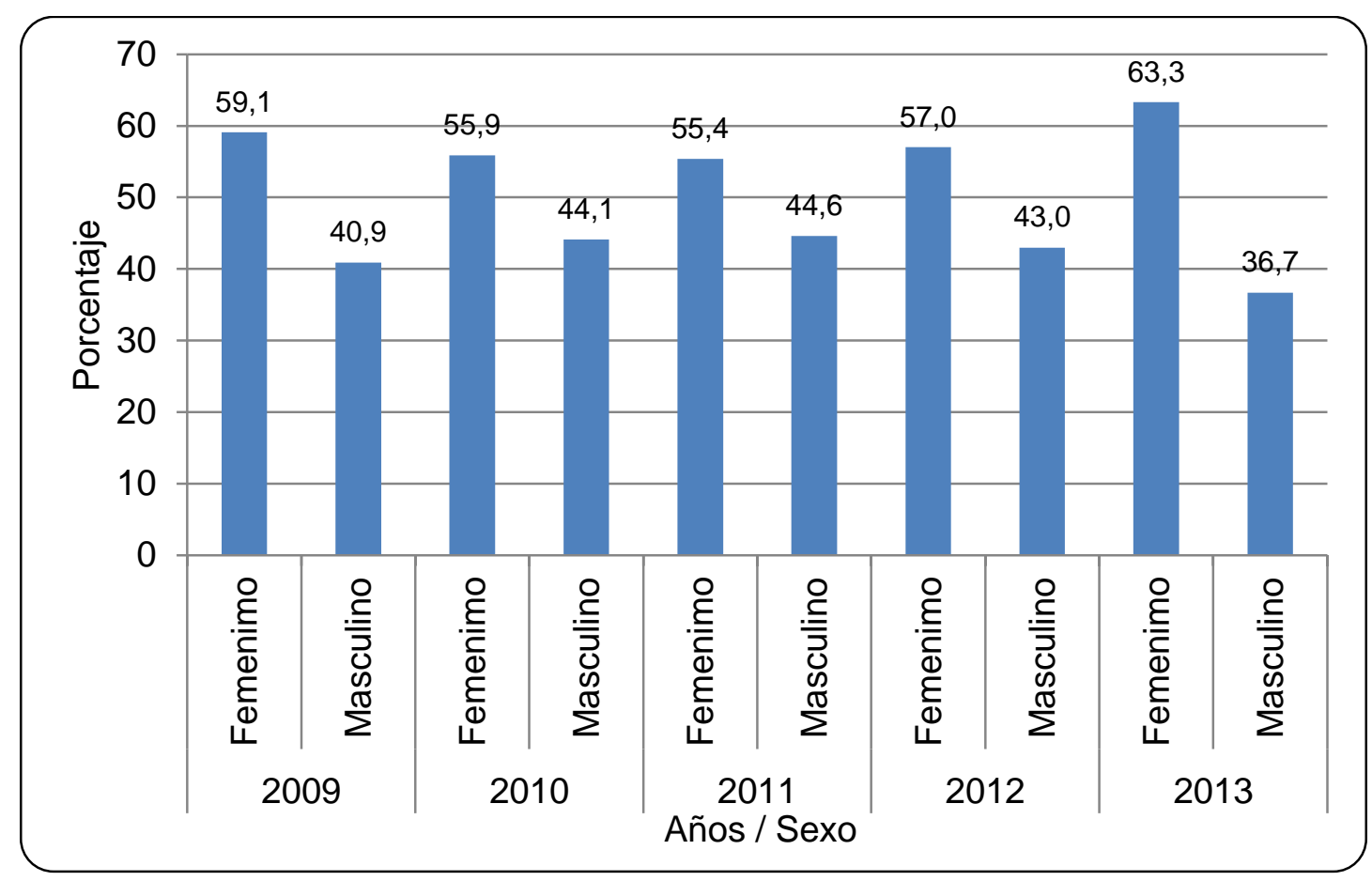

Fuente: Base datos UCIMED, 2014.

\section{Análisis y Conclusiones}

El estudio tiene varias limitaciones, se analiza solo el primer semestre del primer año de la carrera, lo que permite detectar solamente las diferencias obtenidas en relación al éxito o no de los estudiantes que están más directamente relacionadas con los criterios de admisión. A niveles superiores de la carrera, intervienen otras variables académicas y de "selección natural“, para determinar el grupo que se mantiene en la carrera.

Se estudió solo el grupo que tuvo o no éxito académico en relación con criterios de admisión, pero no se analizaron otras posibles causas de esos resultados. Tales como las referentes a los ambientes académicos, la metodología docente, dedicación del tiempo al trabajo, entre otros. 
A pesar de estas limitaciones, el estudio permite extraer conclusiones importantes. La población de estudiantes de primer semestre de Medicina ingresa a la Facultad por medio de un proceso único, que involucra parámetros homogéneos de selección, lo que hace que el grupo estudiantil tenga características similares desde el punto de vista académico.

El desempeño durante el primer semestre de la carrera es un parámetro importante para establecer las posibilidades de retención en la misma, así, al escoger aquellos estudiantes que tienen más posibilidades de éxito en ese primer año, es muy probable que los retiros y la deserción estudiantil disminuyan.

Sería importante analizar si el rendimiento académico está influenciado por factores tales como el tipo de profesor, la metodología utilizada para la enseñanza, los índices de capacidad de atención de los estudiantes, entre otros, como lo demuestran estudios realizados en otros países al inicio de primer semestre de la carrera.

No se encuentran diferencias entre los estudiantes que provienen de áreas fuera del Valle Central, con los que provienen del área urbana, lo que podría estar señalando que el grupo estudiantil tiene condiciones académicas y familiares semejantes.

La admisión es un proceso complejo que involucra balancear varios aspectos; un buen estudiante, éxito en los cursos, necesidades económicas, variables sociales y de fuerza laboral.

Los resultados son esperables si se analiza que las materias propias del primer semestre de la carrera tienen relación con aquellas que han sido vistas en la secundaria. Además, las metodologías de estudio no varían mucho en ambos niveles.

En general, se puede decir, que los estudiantes que ingresan mediante el proceso de admisión establecido en la UCIMED, y que fueron exitosos en el primer semestre de la carrera de Licenciatura en Medicina y Cirugía, se caracterizan por tener mejores promedios, en la prueba 
Influencia de las variables de admisión sobre el éxito académico en el primer año de la carrera de Licenciatura en Medicina y Cirugía de UCIMED

Hilda M. Sancho Ugalde, Juan C. Vanegas Pissa

de conocimientos y en el promedio del colegio y haber tomado la decisión de estudiar con un mayor tiempo de reflexión.

\section{Referencias}

Banco Centroamericano de Integración Económica. (2010). Ficha estadística de Costa Rica. Recuperado de: www.bcie.org/uploaded/content/article/271417695

Boucourt, J. \& González, M. (2006). Perfil socioeconómico y demográfico del estudiante de nuevo ingreso a la Universidad del Zulia. Análisis comparativo cohortes 98-99; 99-2000; 2000-2001; 2001-2002. Revista venezolana de ciencias sociales, 10(1), 86-105.

Carrión, E. (2002). Validación de características al ingreso como predictores del rendimiento académico en la carrera de medicina. Educación Médica Superior, Ciudad de la Habana, $16(1), 5-18$.

De Garay, A. \& Sánchez, R. (2011). La modificación de la política de admisión en la UAM y los cambios en las trayectorias escolares al primer año de estudios en la Unidad Azcapotzalco. Perfiles Educativos, XXXIV (135), 78-99.

Di Gresia, L., Porto, A. \& Ripani, L. (2002). Rendimiento de Los Estudiantes De Las Universidades Públicas Argentinas. Documento de Trabajo Nro. 45 Noviembre 2002. Recuperado de: http://www.depeco.econo.unlp.edu.ar/doctrab/doc45.pdf

Díaz, L. \& Toloza, C. (2007). Los indicadores de selección para el ingreso a la universidad y su valor para estimar el rendimiento académico en el primer semestre. Revista CIMEL, 12 (2), 59-65.

García, M., Alvarado, J. \& Jiménez, A. (2000). La predicción del rendimiento académico: regresión lineal versus regresión logística. Psicothema, 12 (2), 248-252

Hosmer, D. W. \& Lemeshow, S. (2000). Applied Logistic Regression. Second Edition. John Wiley \& Sons, Inc. 147-156.

Ibarra, M. \& Michalus, J. (2010). Análisis Del Rendimiento Académico Mediante Un Modelo Logit. Ingeniería Industrial. Año 9, № 2, 47-56.

IESALC-UNESCO. (2008). La educación superior en América Latina y el Caribe: diez años después de la Conferencia Mundial de 1998. Recuperado de: https://www.google.co.cr/url?sa=t\&rct=j\&q=\&esrc=s\&source=web\&cd=1\&ved=0ahUKE wimnfy_0e3KAhXHdh4KHU6WAxsQFggaMAA\&url=http\%3A\%2F\%2Fwww.iesalc.unes co.org.ve\%2Fdmdocuments\%2Fbiblioteca\%2Flibros\%2FA_diez_anos_dela_conferenc ia_mundial.pdf\&usg=AFQjCNFZeVcZszGI1VDGfbWT3xnsV 4 WDzA\&bvm=bv. 1139436 65 ,d.dmo\&cad=rja 
Iturra, J. \& Soto, R. (2013). Incidencia de factores socioculturales como ruralidad y género en el rendimiento académico del primer semestre de estudiantes de la carrera de $\begin{array}{lllll}\text { cinesiología. } & F E M . & 16 & \text { (3), 153-157. Recuperado de: }\end{array}$ http://scielo.isciii.es/scielo.php?pid=S2014-98322013000300006\&script=sci_arttext

Jara, D., Velarde, H., Gordillo G., Guerra G., Arroyo, C. \& Figueroa, M. (2008). Factores influyentes en el rendimiento académico de estudiantes de primer año de medicina. Revista Anales de la Facultad de Medicina. Universidad Nacional Mayor de San Marcos. 69(3), 193-197.

Javariz, G. (2007). Perfil de estudiantes de nuevo ingreso 2006-2007, Universidad de Puerto Rico en Aguadilla. Recuperado de: http://www.uprag.edu/uploads/opei/Perfildeestudiantesdenuevoingreso20062007.pdf

Kay-Lambkin, F., Pearson, S.A. \& Rolfe, I. (2002). The influence of admissions variables on first year medical school performance: a study from Newcastle University, Australia. Medical Education. 36, 154-159.

Programa Estado de la Nación. (2013). Cuarto Informe Estado de la Educación. Recuperado de: http://www.estadonacion.or.cr/estado-educacion/educacion-informe-ultimo

Rodríguez, M. \& Gómez, V. (2010). Indicadores al ingreso en la carrera de medicina y su relación con el rendimiento académico. Revista Educación Superior, 39 (153), 43-50.

Sancho, H. \& Vanegas, J. (2015). Perfil Socio Demográfico y Académico-Cultural de los Estudiantes de Nuevo Ingreso a la Universidad de Ciencias Médicas, Periodo 20102014. Revista Calidad en la Educación Superior, 6 (1), 1-18.

Santelices, M. V. (2007). Procesos De Admisión A Instituciones De Educación Superior En El Mundo: Antecedentes Bibliográficos. Para La Consideración De Criterios Complementarios En El Proceso De Admisión A La Pontificia Universidad Católica De Chile. Recuperado de: http://www7.uc.cl/webpuc/piloto/pdf/evidencias1.pdf

Santos, Y., Marzabal, Y., Wong, L., Franco, P. \& Rodríguez, K. (2010). Factores asociados al fracaso escolar en estudiantes de medicina del Policlínico. Rev. Med. Electrón. 32(2). Recuperado de: http://scielo.sld.cu/scielo.php?script=sci_arttext\&pid=S168418242010000200006

Tünnermann, C. (2010). Las conferencias regionales y mundiales sobre educación superior de la UNESCO y su impacto en la educación superior de América Latina. Universidades. LX (47), 31-46. 
Influencia de las variables de admisión sobre el éxito académico en el primer año de la carrera de Licenciatura en Medicina y Cirugía de UCIMED

Hilda M. Sancho Ugalde, Juan C. Vanegas Pissa

UNESCO. (1998). Declaración Mundial Sobre La Educación Superior En EI Siglo XXI: visión y acción. Recuperado de: http://www.unesco.org/education/educprog/wche/declaration_spa.htm

UNESCO. (2006). Informe Sobre La Educación Superior en América Latina y El Caribe. 20002005. Recuperado de: www.iesalc.unesco.org.ve/index.php?option...

Vélez, A. \& Roa, C. (2005). Factores asociados al rendimiento académico en estudiantes de medicina. Revista Educación Médica. 8(2), 74-82. 